\title{
EXTENSÃO UNIVERSITÁRIA E O MUNDO DO
}

TRABALHO

DOI: $d x$. doi.org/10.18616/inser04

Reinaldo Luiz Xavier Tillmann ${ }^{1}$

\section{INTRODUÇÃO}

O tema aqui proposto pode se prestar a diversas análises, conforme o direcionamento do olhar sobre o mundo do trabalho e sobre a universidade. Por conseguinte, existem diversas concepções a respeito de universidade e trabalho, bem como visões que associam e dissociam esses dois elementos da realidade.

Neste capítulo, pretende-se analisar a universidade, em especial o seu caráter extensionista, a partir de uma imbricação entre academia e mundo do trabalho. É impossível analisar de forma crítica a extensão universitária se considerarmos uma dissociação entre teoria e prática, como se houvesse um conhecimento exclusivo da academia e outro exclusivo do mundo do trabalho.

A forma de associação da universidade com o mundo do trabalho não pode desprezar as especificidades de cada realidade que, justamente, concedem a ela originalidade e autonomia. Associar trabalho e universidade é, fundamentalmente, reforçar a autonomia de cada um e entender que não existe dependência, hierarquia ou precedência temporal entre eles. $\mathrm{O}$ que existe é uma construção conjunta; assim, ao desprezar esse imperativo da realidade, tanto o trabalho como as universidades se tornam idealizados e cumpridores de uma função social de alienação, pois, de um lado está a ${ }^{1}$ Mestre em Desenvolvimento Social (UCPEL) e Mestre em Educação (UFPEL). E-mail: reinaldo.tillmann@ucpel.edu.br 
universidade, que entende como possível a construção de um projeto pedagógico no qual o mundo do trabalho não tenha centralidade como fator real de alimentação de todo e qualquer conhecimento, e, de outro, estão as articulações do mundo do trabalho, que desprezam a academia como um fator de real importância para o entendimento e a emancipação do trabalho das teias que o tornam eternamente dependente do mundo do capital.

Essa separação, ainda fortemente presente entre trabalho intelectual e trabalho braçal, representa mais que um preconceito, representa uma visão que se perpetua como cultura arraigada de dois mundos que não se comunicam, porque, ao não se comunicarem entre si, o trabalho é só trabalho e o conhecimento é só conhecimento.

A cultura fortemente arraigada permite simplesmente um conhecimento para potencializar o trabalho e um trabalho para transmitir o conhecimento, ou seja, não é permitido um entrelaçamento total e real das autonomias já referidas, pois o que interessa é um entrelaçamento parcial e superficial.

Entendo que a universidade, por meio de sua política de extensão, pode se deslocar desta lógica perversa de dissociação, que aqui será apresentada, estabelecendo uma real interação com a comunidade a partir de um processo dialético de comunhão de conhecimentos e não de mera prestadora de serviços.

Para desenvolver com mais profundidade essa ideia de universidade, pretendo analisar com mais vagar e apoio teórico uma concepção crítica sobre a extensão universitária e relatar a história de minha experiência em um projeto de extensão que dialogou com o mundo do trabalho.

Nessa tentativa de aproximar minhas vivências como extensionista em um projeto da incubadora tecnológica de cooperativas populares, aprofundando uma visão crítica sobre a academia e o mundo do trabalho, sem dúvida, realizei um esforço descritivo muito grande, afinal, o que des- 
crevi é justamente minha atuação no projeto, não a visão dos trabalhadores e/ou de outros operadores dele participantes.

Na verdade, embora a técnica utilizada seja considerada descritiva, a reflexão crítica sobre o problema apresentado, da relação deficitária entre a universidade e o mundo do trabalho, só foi possível ser construída a partir da vivência do autor com as experiências relatadas, o que, sem dúvida, aproxima o método de busca dos objetivos fortemente arraigados à pesquisa-ação.

\section{A UNIVERSIDADE E OS QUESTIONAMENTOS DA MODERNIDADE}

Não entendo como possível a análise com profundidade da academia universitária sem avançar minimamente no entendimento de ciência e de sua relação com a sociedade, com o cotidiano das pessoas ditas comuns, ou seja, que não participam ativamente de atividades de ensino e pesquisa, tarefa essa reservada a uma minoria que habita as academias encarregadas dessas tarefas ou atividades. Nesse sentido, pergunto, portanto: O que é ciência? Qual é a sua serventia?

Esses simples questionamentos são fundamentais para indagarmos se a produção científica das universidades tem utilidade (serventia) para a sociedade. Tais questionamentos, porém, não denotam respostas rápidas e simples, sob pena de serem superficiais e abstratas.

É importante trazer esse mesmo questionamento feito por Jean-Jacques Rousseau, em 1750, ao tratar do progresso das ciências na modernidade: 
Há alguma relação entre a ciência e a virtude? Há alguma razão de peso para substituirmos o conhecimento vulgar que temos da natureza e da vida e que partilhamos com os homens e mulheres de nossa sociedade pelo conhecimento científico produzido por poucos e inacessível à maioria? Contribuirá a ciência para diminuir o fosso crescente na nossa sociedade entre o que se é e o que se aparenta ser, o saber dizer e o saber fazer, entre a teoria e a prática? (ROUSSEAU, 1971, p. 52).

Na verdade, Rousseau respondeu com um não a todos os questionamentos feitos por ele próprio, selando, assim, um julgamento da produção científica e de suas utilidades naquele período.

Importa salientar que o momento histórico da resposta de Rousseau era de transição de um período científico em que a ciência estava associada a fatores naturais e místicos, influindo diretamente na vida dos indivíduos, para um período (a partir do século XVI) em que o pensamento científico passara a se pautar pela racionalidade, pelo cálculo, pela prova objetiva do que é afirmado.

A modernidade questiona profundamente a utilidade do pensamento e da produção científica, desconfiando de tudo que não se consegue ser provado cientificamente. Nesse passo, a modernidade construiu uma ciência e procedimentos científicos que afastam o pensador da realidade, pois, para provar e dar validade acadêmica ao seu pensar, deve-se submeter a procedimentos de extrema racionalidade que escapam, inclusive, da preocupação inicial da própria modernidade de se afastar do conhecimento mítico.

O tempo da modernidade, embora de transformações marcantes no campo científico, parece que não conseguiu se afastar concretamente da origem mítica do conhecimento, pois, aparentemente, ela criou outro mito: o mito da racionalidade. Não teríamos mais sacerdotes, magos, profetas e suas previsões, mas teríamos cientistas, professores e laboratórios, 
que, da mesma forma, legitimariam uma forma especial e temporal de conhecimento ${ }^{2}$.

O que mais impressiona no período moderno é que justamente por não ter respondido a uma de suas questões fundamentais (verbalizadas por Rousseau), a atual universidade ${ }^{3}$ continua com as mesmas questões. Simples e sem respostas.

Nesse sentido, são pertinentes as observações de Marlene Ribeiro sobre a universidade brasileira:

[...] este preâmbulo serve para situar a crise da universidade brasileira, vivenciando dilemas próprios da pós-modernidade, ao mesmo tempo em que enfrenta exigências que seriam próprias da modernidade, especialmente no que se refere à produção de ciência e tecnologia (RIBEIRO, 1999, p. 05).

$\mathrm{Na}$ verdade, Ribeiro retrata que a universidade não conseguiu cumprir com as promessas emancipatórias da modernidade, ao mesmo tempo que se depara, no cotidiano, com as mesmas questões. A visão crítica da educadora quer demonstrar a possibilidade de construção de uma universidade democrática (inclusiva) e competente (produção de ciência e tecnologia socialmente articulada), sendo o viés da extensão universitária um caminho privilegiado para atingir esse fim.

${ }^{2}$ Concepção a partir da Dialética do Iluminismo, de Theodor Adorno e Max Horkheimer (1985).

${ }^{3}$ A universidade pós-moderna não excluiu a universidade moderna. As duas coabitam na contemporaneidade. Concepção de Marlene Ribeiro: universidade brasileira "pós-moderna" (democratização x competência). 


\section{EXTENSÃO UNIVERSITÁRIA: UMA RESPOSTA SIMPLES}

Sem pretender definir extensão universitária, pode-se trabalhar a concepção de que o entendimento sobre extensão é sempre o de alcançar algo já existente, de estender para fora algo que é típico de determinado ambiente. No limite, pode-se pensar a extensão como uma dilatação do conhecimento produzido.

Noto que a extensão universitária não busca o novo e não interage com a sociedade, pois ela simplesmente presta um serviço (assistência judiciária, atendimento odontológico, serviços ambulatoriais, etc.) do qual a universidade detém o conhecimento e quer estendê-lo por razões diversas, ou seja, a universidade - lócus de produção científica - não aprende com o ambiente da extensão, simplesmente oferece o conhecimento e a verdade internamente produzidos. Admite-se, no máximo, um processo de alteração pontual de algumas práticas universitárias pela dilatação do conhecimento estendido.

Na verdade, os caminhos da extensão universitária só podem levar a duas situações, conforme nos relata Marlene Ribeiro a partir de experiências em projetos de extensão do NEPE (Núcleo de Estudos, Experiências e Pesquisas Educacionais), da Faculdade de Educação da Universidade do Amazonas:

Penso que a finalidade da extensão universitária não é, de modo algum, substituir o Estado na oferta de serviços básicos, nem os membros da comunidade no seu papel de reivindicar seus direitos e exercer sua cidadania. Daí a importância desta experiência para fundamentar tanto o trabalho que o NEPE vem desenvolvendo como o que a universidade pretende com trabalhos, em parceria com a comunidade, que podem caminhar em dois sentidos opostos: ou o da dependência ou o do questionamento ao 
papel social da instituição universitária e de sua relação com a comunidade. (RIBEIRO, 1999, p. 220).

Entendo que os conhecimentos produzidos pelas universidades, de uma forma geral, não se alteram pela interação dialética com outros modos de conhecimento, mas, simplesmente, eles se modificam a partir de sua própria dilatação, ou seja, a produção e a transformação dos conhecimentos se operam exclusivamente dentro da academia, mesmo quando esta realiza atividades de extensão.

Por evidente, essa situação fática de relacionamento entre universidade e comunidade traz em seu bojo cruciais relações de poder que aprisionam a sociedade a uma lógica de subordinação e conformação a espaços previamente delimitados, os quais são ocupados de forma privilegiada, conforme uma relação entre poder e saber. É o que observamos nas constatações que Ribeiro aponta:

Outro autor que analisa as relações entre poder e saber e que amplia a compreensão de questões colocadas pelo NEPE, sobre os saberes subalternos na reformulação curricular e sobre os trabalhos de extensão, é Michel Foucault. Para este autor, saber e poder encontram-se reciprocamente articulados em práticas particulares, localizadas e datadas. Ao se referir ao que denomina insurreição dos saberes dominados, Foucault expressa seu entendimento sobre duas espécies de saberes. Um deles refere-se aos conteúdos históricos concernentes às lutas e confrontos, que são omitidos nas sistematizações formais pelo seu caráter revelador e crítico. Outro refere-se ao saber "desqualificado" do povo, que não é legitimado pelo estatuto de conhecimento científico. $\mathrm{O}$ saber dominado, diferenciado, incapaz de homogeneidade, particular, paralelo e marginal ao saber científico e competente deve sua força à crítica que faz a este último. Tanto o primeiro, saber 
histórico, erudito, oculto, quanto o outro, "desqualificado" e "não competente", apesar do paradoxo, tratam, segundo Foucault, do saber histórico das lutas e da memória até então subordinada dos combates. Esse acoplamento dos saberes que possibilita a construção de um saber histórico das lutas e a utilização deste saber em táticas atuais dos movimentos emancipatórios é o que Foucault chama, provisoriamente, de genealogia. (RIBEIRO, 1999, p. 229-230).

A universidade, nas suas atividades de extensão, não só está disposta a aprender com as situações e espaços com que se comunica, mas também apreender essas situações e espaços a uma lógica acadêmica - que tenta ser hegemônica ${ }^{4}$ - e que foi um pressuposto da modernidade quando a universidade centralizava a produção cultural e o conhecimento científico. De acordo com o que relata Santos (1997, p. 193), percebemos que “[...] a centralidade da universidade enquanto lugar privilegiado da produção de alta cultura e conhecimento científico avançado é um fenômeno do Século XIX, do período do capitalismo liberal [...]”.

É preciso pensar um novo modelo de universidade, que não despreze e ignore o conhecimento que é gerado fora dela. Uma universidade deve, no meu entendimento, centrar forças no papel da extensão, não como prestação de serviços ou estratégia de publicidade, mas como o mais importante elemento de alimentação de seu banco de conhecimentos.

A ideia de uma universidade que detém a razão e a verdade sobre todas as situações fáticas deveria estar superada com a modernidade, porém parece que continua a absorver ou apreender, ao invés de sorver e aprender com a realidade.

Entendo que Santos é perspicaz ao pensar uma ideia de universidade, apontando com clareza a contradição atual do modelo universitário. $\mathrm{O}$ autor revela que

${ }^{4}$ Santos, 1997, p. 193-200. 
Um pouco por todo o lado, a universidade confronta-se com uma situação complexa: são lhe feitas exigências cada vez maiores por parte da sociedade, ao mesmo tempo em que se tornam cada vez mais restritivas as políticas de financiamento de suas atividades por parte do Estado. Duplamente desafiada, pela sociedade e pelo Estado, a universidade não parece preparada para defrontar os desafios, tanto mais que estes apontam para transformações profundas e não para simples reformas parcelares. Aliás, tal impreparação, mais do que conjuntural, parece ser estrutural, na medida em que a perenidade da instituição universitária, sobretudo no mundo ocidental, está associada à rigidez funcional e organizacional, à relativa impermeabilidade às pressões externas, enfim, à aversão à mudança. (SANTOS, 1997, p. 187).

Diante desses fatos que Santos expõe, percebemos que estamos pensando em uma universidade contemporânea dentro de paradigmas funcionais típicos da modernidade, que caracterizam uma universidade engessada em suas próprias verdades, a qual desconhece ou quer desconhecer o que acontece em termos de conhecimento fora de suas fronteiras.

Essa tendência moderna (da modernidade) de o conhecimento ser provado por critérios racionais, que só existem nas academias, tem conflitado o pensar a universidade na atualidade, visto que a própria universidade tem sido analisada por critérios diversos e inimagináveis, durante o período moderno, ou seja, a sociedade não vê mais a academia como espaço exclusivo de produção e certificação do conhecimento; ao mesmo tempo, exige dela respostas pontuais e pragmáticas aos problemas que enfrenta no cotidiano. A verdade é que enquanto a universidade não se pautar por essa nova realidade e continuar com os pés fincados na modernidade, certamente não encontrará instrumentos que possibilitem a sua real transformação. 
Parece incrível que a universidade continue existindo dentro do tripé investigação, ensino e prestação de serviços (SANTOS, 1997, p. 188), como se detivesse a exclusividade da pesquisa (investigação) sobre a complexidade do mundo atual e, ainda, arvorar-se como o meio mais competente de propagação - por meio do ensino - das conclusões, frutos da investigação.

A prestação de serviços (extensão), por sua vez, seria uma concessão feita à sociedade para demonstrar utilidade e justificar sua existência. É o que Santos denuncia ao concluir que:

A teorização hoje dominante dos programas de extensão é reveladora dos limites da abertura da universidade à comunidade e dos objetivos que the subjazem. Em primeiro lugar, a abertura desempenha um importante papel de relações públicas em comunidades com longo rol de queixas e ressentimentos contra a universidade, desde as isenções fiscais ao expansionismo das infraestruturas, em detrimento de outras atividades locais, e ao desassossego causado pela boemia estudantil. (SANTOS, 1997, p. 208).

A academia tem que apostar, de forma decisiva, na extensão universitária como um elemento de renovação de seu conhecimento, de alimentação para uma realidade que se constitui fora dos muros da academia e que vem ocupando um espaço que muitas vezes já foi ocupado pela própria universidade de forma hegemônica.

A extensão universitária não deve, todavia, configurar-se como um elemento de reconquista da hegemonia perdida desde a modernidade, mas como uma aceitação de que o conhecimento não é produzido somente pela academia, constatação presente, como cita Santos, na dicotomia "alta cultura x cultura de massas", típica da modernidade, quando a universidade 
era produtora de uma cultura sujeito (alta cultura) e tornava seu objeto as culturas de massas.

A cultura de massas tem uma lógica de produção, de distribuição e de consumo completamente distinta e muito mais dinâmica da que é própria da cultura universitária, e os seus produtos vão apertando o cerco à alta cultura universitária, quer porque reciclam constantemente os produtos desta, quer porque concorrem com ela na formação do universo cultural dos estudantes. Incapaz de transformar esta nova forma cultural numa cultura-objeto, a universidade deixa de ser o produtor central de cultura-sujeito e nessa medida perde centralidade. (SANTOS, 1997, p. 193).

$\mathrm{Na}$ realidade, a própria modernidade não conseguiu suportar a velocidade e o dinamismo das relações sociais e, enclausurada em sua prova racional, esqueceu-se de que novos mecanismos de produção e comprovação do saber desenvolviam-se em diversos campos onde a universidade não existia ou só existia com uma prática extensionista tradicional , dizer a verdade da academia.

É preciso que uma universidade se estruture a partir de uma nova concepção de produção e disponibilização do conhecimento.

\section{COMO CONSTRUIR UMA NOVA UNIVERSIDADE?}

Não há resgate possível, talvez nem haja o que resgatar. É preciso criar o novo e se alimentar dele. O compositor Vitor Ramil, em um trabalho do ano de 1995, tem um dizer (e cantar) extremamente adequado ao momento de nossa universidade: "Com que roupa eu vou?/ Mais que o 
velho, o novo já gastou/ Mais que um pano novo/ Eu quero pôr/ Um novo à beça/ À beça, à beça”.

A universidade, como na citação de Santos, encontra-se perplexa diante das ameaças à sua centralidade acadêmica operada por fora de suas fronteiras e potencializada por sua total incompetência interna, a fim de transpor os ditames da modernidade rígida, funcional, e ingressar em uma ideia de universidade permeável e dialógica.

Não basta, portanto, usar métodos velhos e gastos, que já se comprovaram superados. Ocorre que também não é possível entender a contemporaneidade como um período "mágico", uma época que irá operar as transições necessárias no meio universitário, simplesmente pela transposição paradigmática de valores e conceitos. Transitar da racionalidade para a subjetividade, da robótica para a informática, da aferição para a emoção não representa necessariamente o novo que poderia, por possíveis mudanças paradigmáticas, transformar a prática universitária.

É preciso mais que o novo, é preciso uma transformação paradigmática, não das ideias, e sim da produção das ideias, as quais não devem ser exclusivas de um espaço acadêmico, mas fertilizar um terreno híbrido de conhecimentos científicos (da academia) e populares (fora da academia). O conhecimento não deve ser classificado por espaços onde seus produtores habitam.

Em 1986, o reitor da Universidade de Brasília, Cristóvan Buarque, apresentou as bases de uma política de extensão que condizem com o que foi afirmado anteriormente, sendo inclusive citado na obra de Santos:

Considera-se que o conhecimento científico, tecnológico e artístico gerado na universidade e institutos de pesquisa não é único. Existem outras formas de conhecimento surgidas da prática de pensar e de agir dos inúmeros segmentos da sociedade, ao longo de gerações, que, por não serem caracterizadas como científicas, são desprovidas de legitimidade institucional. Essas 
práticas estão sendo recuperadas à luz de uma atividade orgânica com a maioria da população. (BUARQUE apud SANTOS, 1997, p. 209).

Isso é um “novo à beça”. É, para mim, uma concepção desejável de universidade contemporânea, universidade de um espaço e de um tempo em que a extensão universitária não se limita a estender ou a dilatar o conhecimento que é produzido internamente, mas que se caracteriza como um diálogo franco e sincero com a realidade e a especificidade de cada local, buscando uma interação pela qual a universidade, operando a extensão de seus conhecimentos, acaba por transformar esses próprios conhecimentos, que, por sua vez, transformarão a realidade local.

\section{EXPERIÊNCIAS DE EXTENSÃO UNIVERSITÁRIA}

A decisão de trabalhar este tópico, sob o formato de experiências e não propriamente de projetos de extensão, deve-se às leituras do pedagogo Anton Semiónovitch Makarenko. A escolha influenciará a forma de exposição com que as atividades serão expostas, procurando realçar mais as vivências pedagógicas que o seu formato acadêmico.

Makarenko valorizava de forma extrema suas experiências pedagógicas, inclusive revelando que jamais alcançaria sucesso com seus coletivos pedagógicos (em especial, a Colônia Gorky) sem a valorização da prática, do cotidiano, do dia a dia das atividades nas colônias infantis onde coordenava. O pedagogo defrontou-se com um desafio: a construção de um homem novo para servir aos ideais da revolução soviética. A forma com que encarou esse desafio foi exercendo uma distância crítica da burocracia soviética e uma falta de apego às teorias existentes (que, na verdade, eram inexistentes ao caso concreto), procurando teorizar a partir das vivências das colônias e, principalmente, do risco constante de fracassar. 
Os primeiros meses da nossa colônia foram, para mim e para meus companheiros, não só meses de desespero e esforço impotente, foram também meses de procura da verdade. Em toda minha vida, eu não li tanta literatura pedagógica quanto naquele inverno de 1920. [...] Quanto a mim, o resultado principal dessas leituras foi uma convicção firme e, subitamente, não sei por que, fundamental, de que, em minhas mãos, não existia nenhuma ciência nem teoria nenhuma, e que a teoria tinha de ser extraída da soma total dos fenômenos reais que se desenrolavam diante dos meus olhos. No começo, eu nem sequer compreendi, mas simplesmente vi que eu precisava não de fórmulas livrescas, as quais não podiam se aplicar aos fatos de qualquer maneira, mas de uma análise imediata e de uma ação não menos urgente (MAKARENKO, 2005, p. 21-22).

A partir dessas colocações de Makarenko, observo que minha atuação nos programas de extensão na Universidade Católica de Pelotas, onde participei ao longo dos anos, tem similitude com o dilema retratado anteriormente. Abordarei somente um dos projetos de extensão em que atuei, relatando o período de seu surgimento e consolidação.

\section{A EXPERIÊNCIA DA INTECOOP/ UCPEL ${ }^{5}$}

A Universidade Católica de Pelotas ingressou na rede de incubadoras no ano de 2000, época em que outras 13 incubadoras universitárias já faziam parte da rede, inclusive com financiamentos aprovados na FINEP (Financiadora Nacional de Estudos e Projetos). É esse período que des-

\footnotetext{
${ }^{5}$ A experiência refere-se ao espaço temporal de surgimento e consolidação da incubadora (20002004). Hoje a INTECOOP/UCPEL tem uma estrutura e funcionamento diferenciado, além de estar identificada como NESIC (Núcleo de Economia Solidária e Incubação de Cooperativas). A incubadora atualmente pertence à rede de incubadoras populares, desligando-se da Unitrabalho no processo de constituição da nova rede.
} 
crevo, pois representa um tempo de muita construção coletiva e interação dialética entre professores e estudantes de áreas diferenciadas, bem como entre a universidade e o mundo do trabalho.

A incubadora surgiu a partir de uma discussão democrática entre um grupo de professores pertencentes ao núcleo local da Unitrabalho, que questionou sobre um projeto de desenvolvimento para a metade sul do Rio Grande do Sul, em especial para a cidade de Pelotas.

Após várias reuniões e projetos alinhavados, embarcamos na concepção de economia solidária por meio da participação em grupos de estudos e seminários nacionais sobre o tema, o qual, associado à ideia de autogestão, pela participação da ANTEAG nos encontros, uniu o grupo que se pautava por uma proposta de desenvolvimento que contemplaria o trabalho como o fator principal do projeto.

O grupo, enfim, entendeu que não podia ficar atrelado à formulação do desenvolvimento pela atração de empresas e/ou pelo incentivo e capacitação ao empreendedorismo, entendido aqui o empreendedor como aquele que quer arriscar determinada quantia de capital em um investimento produtivo.

Necessário se fazia pensar o desenvolvimento a partir do trabalho, ou seja, o trabalhador não mais objeto do detentor de capital e sua respectiva capacidade gerencial, mas o próprio trabalhador como sujeito do desenvolvimento e gestor de seu empreendimento.

A autogestão de empresas coletivas pelos trabalhadores referendou nossa adesão à rede de incubadoras como uma proposta viável de desenvolvimento pelo trabalho na cidade de Pelotas.

Desde o surgimento da incubadora até o fim do período referido, tive a imensa satisfação em coordenar os trabalhos de uma equipe de professores orientados por um projeto interdisciplinar de extensão, o qual enriqueceu os docentes, os acadêmicos e a comunidade onde nos relacionamos. 
Foi uma experiência única, na qual entendo ter apontado fatores de emancipação do trabalho, a partir de uma relação dialógica com um projeto de extensão universitária.

Nossas atividades de funcionamento foram baseadas na experiência do que constatamos em outras incubadoras pelo Brasil, procurando repetir aquilo que avaliávamos bom e aperfeiçoar outros pontos.

Uma das metas foi reforçar o vínculo acadêmico e interdisciplinar do projeto de extensão, ou seja, um olhar para dentro da universidade, visto que, no nosso entendimento, a extensão não poderia se caracterizar como uma atividade que operaria resultados somente fora dos muros da academia. Nesse sentido, foi fundamental as atividades de extensão reformularem o pensar da universidade.

Com esse intuito, organizamos um semestre voltado para discussões internas com a reitoria, escolas e professores interessados, por meio de reuniões, painéis etc.

Após o período de reuniões com a estrutura docente e administrativa da universidade, dialogamos com o que entendemos ser o nosso maior aliado e fator decisivo de sucesso ou fracasso de nosso projeto, ou seja, o setor discente, pois, sem um encantamento e conscientização dos estudantes, nossa proposta de incubação certamente não se concretizaria. Foi preciso conjugar uma aceitação e entusiasmo dos estudantes com uma estrutura interdisciplinar da universidade, experiência, aliás, inédita na UCPEL.

Foi um período difícil, pois fomos pressionados para ir a campo pelas iniciativas cooperadas e associações que nos procuraram e relutamos em cumprir com o dever de casa. Foi um semestre de fortalecimento e criação de alicerces. Creio que isso foi cumprido a contento, embora muito ainda devesse ser feito.

Precisávamos também garantir a continuidade de nossas atividades, então, para isso, fomos buscar parceiros que financiaram o orçamento 
da incubadora que a universidade havia se comprometido a custear pelo período de um ano.

A relaçãojáantiga comaSEDAI/RS(Secretaria deDesenvolvimento e Assuntos Internacionais do Estado do Rio Grande do Sul), em especial com o setor de Economia Popular e Solidária (ECOPOPSOL), aproximou-nos de um recente convênio entre aquela Secretaria e a ANTEAG, de forma que obtivemos financiamento total do nosso custo por parte da ANTEAG.

Nós, juntamente com nossas parceiras, não só financeiras, inclusive a ANTEAG e a SEDAI, articulamos ações e discussões conjuntas, envolvendo outros parceiros, como a Cáritas Diocesana de Pelotas, o CAMP (Centro de Formação Multiprofissional de Porto Alegre), universidades públicas e privadas, associações, ONGs etc., elementos fundamentais dentro da nossa concepção de extensão.

Por fim, chegamos à última parte, que se refere às incubações propriamente ditas. Estávamos trabalhando, à época, com cinco empreendimentos cooperados, cada um em uma fase diferente de maturidade e produção:

- Cooperativa Unimetal: a Unimetal, cooperativa de trabalhadores no ramo metalúrgico, surgiu em Pelotas no dia 03 de setembro de 1999, ocasião em que 22 trabalhadores reunidos em Assembleia Geral aprovaram o estatuto de fundação dessa empresa cooperativa, formalizando, assim, um processo que já se desenvolvia no campo dos fatos há algum tempo. A cooperativa Unimetal surgiu em decorrência de um processo falimentar da empresa Ancar, que trabalhava na recuperação e reparo de ônibus e motorhomes. Foram momentos de muitas dificuldades, vivenciados pelos trabalhadores da antiga empresa, os quais, antes do fechamento definitivo, tinham seus salários atrasados. Quando a falência foi decretada, não houve como receber nenhuma verba rescisória, salvo uma pequena parcela do fundo de garantia, resultado de uma mo- 
bilização intensa. Os trabalhadores, porém, não aceitaram a ideia de aumentarem as estatísticas do desemprego e se organizaram a partir do único patrimônio que possuíam: sua força de trabalho. Dessa força nasceu a Unimetal, um dos mais importantes patrimônios nesse e em outros empreendimentos de economia solidária. A história da Unimetal é fundamentalmente uma história de trabalho, condição e adjetivo fundamental para a constituição de um empreendimento em que os trabalhadores são os sujeitos de sua própria história; uma história que somente eles podem construir - a história de sua emancipação. A equipe de incubação foi orientada por este autor.

- Cooperativa do Loteamento Dunas: a Cooperdunas era uma cooperativa que se dedicava à produção de kits sanitários populares, de baixo custo, produzidos em estrutura de fibrocimento, com acabamento em massa corrida. Esse empreendimento, cuja equipe de incubação era orientada pelo professor Marcus Kammer, só foi constituída em setembro de 2000, sendo resultado de um projeto social denominado "Pró-Renda/RS", envolvendo o governo da Alemanha (GTZ), a secretaria metropolitana do estado do Rio Grande do Sul e a prefeitura de Pelotas, que desenvolveram uma série de projetos no loteamento popular do Bairro Areal, em Pelotas, sendo que um se potencializou na forma de cooperativa.

- Cooperativa de Produtores de Lacticínios: em Canguçu, cidade vizinha do município de Pelotas, a professora Gabriela Scur orientou uma equipe de estagiários que incubava a cooperativa Coopal, empreendimento associativo resultante do desligamento de pequenos produtores de leite (em torno de 250) de uma tradicional cooperativa de produtos lácteos da região. $\mathrm{Na}$ época, a cooperativa já contava com 450 famílias que pretendiam, a partir de 2001, desenvolver sua própria marca e embalar o leite e os iogurtes de frutas da região. 
- Cooperativa de Reciclagem de Lixo: no Bairro Getúlio Vargas (de alta vulnerabilidade social), em Pelotas, desenvolveu-se outra experiência associativa por meio de uma cooperativa de reciclagem de lixo e de produção de vassouras pelo desfibramento de garrafas PET. Na verdade, a cooperativa encaminhou sua documentação para a Junta Comercial no ano 2000, esperando obter o financiamento para a fábrica de vassouras por meio do projeto "Mar de Dentro", do Governo do Rio Grande do Sul, ao concluir as formalidades de sua fundação. As professoras Carmem Júlia Yanke e Rosane Vieira orientaram a equipe de incubação.

- Cooperativa de Novos Valores: em nossa própria Universidade ocorreu uma situação de terceirização dos serviços de limpeza por meio de uma cooperativa que não parecia atender aos princípios do cooperativismo. Os trabalhadores associados nos procuraram para reclamar da situação difícil que estavam enfrentando. Passamos a assessorá-los na formação de uma nova cooperativa, que, após vencer um processo de licitação, prestou serviços na nossa universidade, com qualidade e respeito aos princípios cooperativistas. A Coopernova teve a incubação orientada pelas professoras Ana Luiza Xavier Barros e Eliana Moura.

\section{A EXPERIÊNCIA DA EXTENSÃO E A EMANCIPAÇÃO NO MUNDO DO TRABALHO}

Em primeiro lugar, a experiência demonstrou um efeito interno (academia) na formação dos estagiários que desenvolveram esse tipo de experiência, por encontrarem um campo rico e diversificado de situações e dificuldades que deveriam resolver a partir dos conhecimentos que adquiriram na própria academia. 
Os estagiários perceberam que sua formação para o trabalho não era abstrata, bem como que muitas dificuldades intransponíveis poderiam ser superadas pela disponibilização de suas formações universitárias.

O quadro em relação aos estagiários ainda era muito recente para uma verificação mais precisa, porém reuniões de avaliação e relatos de atividades demonstraram, com alguma clareza, a transformação no processo de aquisição e disponibilização de conhecimento por parte dos estudantes envolvidos nas atividades de incubação de empreendimentos solidários.

O espaço no qual pudemos verificar os efeitos claros de emancipação do trabalho era nos empreendimentos solidários, onde o trabalhador, em geral, encontrava-se em uma situação de total falta de recursos para iniciar o seu empreendimento, contando simplesmente com sua força de trabalho e uma vontade de superação da situação de penúria em que se encontrava.

É importante relatar que em todos os empreendimentos, superada a dificuldade inicial (que era constante) de falta de recursos, os trabalhadores associados se defrontaram com um problema maior, ou seja, a formação cultural para exercer uma função de gestão de um empreendimento, principalmente de uma empresa coletiva e solidária.

O caminho de superação dessa alienação imposta pelo capital ao trabalho é o caminho da emancipação de cada um e de todos os trabalhadores envolvidos nos processos de empresas solidárias e autogestionárias.

A afirmação de que as Incubadoras Tecnológicas de Cooperativas Populares apontavam para a emancipação do trabalho em relação ao Capital é justamente pelo caráter educativo que atravessava esse programa de extensão. Entenda-se esse viés educativo não como uma transferência unilateral de conhecimentos e técnicas de gestão e produção, mas como uma duplicidade de experiências entre a universidade e o mundo do trabalho.

Ocorre que, nesse caminho de mão dupla, o mundo do trabalho vai se transformando como sujeito de sua própria transformação, pois os 
trabalhadores das cooperativas incubadas vão tendo conhecimento e consciência da totalidade de um processo de gestão e produção da qual eles só faziam parte como objetos parciais de uma engrenagem produtiva, que somente funcionava com a venda de sua força de trabalho ao capital.

É de se notar que ao mesmo tempo que as condições objetivas dos trabalhadores iam melhorando, por causa da alteração da realidade que os cercava no local de trabalho, também os trabalhadores iam se autotransformando em seu cotidiano.

Marx (apud DUSSEL, 2000, p. 508) já se referia a essa possibilidade como uma práxis revolucionária ${ }^{6}$ : "A coincidência da transformação das circunstâncias com a da atividade humana ou autotransformação só pode ser concebida racionalmente como práxis revolucionária”.

$\mathrm{Na}$ verdade, a emancipação não exige nada mais que o próprio trabalho como condição de sua implementação, porém a universidade pode contribuir em muito para este desiderato, por meio de programas de extensão que articulem, no trabalho, um princípio educativo o qual já se encontra lá presente, porém camuflado pelos interesses de uma organização da economia, que funciona com a primazia do capital sobre o mundo do trabalho.

Importante frisar que, nessa duplicidade dialética, não cabe à universidade somente um espaço de colaboração com os trabalhadores, mas, fundamentalmente, os trabalhadores também influenciam, de forma contundente, na alteração do papel social da universidade.

A questão que ainda me parece distante é como os trabalhadores poderão contribuir efetivamente para um projeto novo da universidade se o que se mostra é uma total carência de condições objetivas de sobrevivência, em que o conhecimento produzido pelas universidades opera muito mais efeitos de subordinação aos trabalhadores, quer pela introdução de novas tecnologias quer por complexos teoremas de explicações de realida-

${ }^{6}$ Dussel entende que Marx confunde, na citação, revolução e transformação ética. 
des, do que propriamente uma condição propícia para uma comunicação entre o mundo do trabalho e a academia universitária.

\section{CONSIDERAÇÕES FINAIS}

A pergunta importante ao que foi afirmado anteriormente seria: por que um processo produtivo (trabalho coletivo) poderia ser considerado dotado de um princípio educativo próprio e com condições de dialogar com outro processo educativo típico da academia universitária? A resposta encontra-se na forma como a gestão do conhecimento estava consolidada naquele determinado processo produtivo, se aquele conhecimento lá gerado teria condição de gerar alienação ou emancipação.

A alienação produziria trabalhadores desprovidos da educação pelo trabalho, enquanto a emancipação seria o resultado possível de um processo autogestionário, o qual dialogaria com o projeto de extensão relatado. Creio ser importante deixar muito claro que a compreensão da emancipação ou da subordinação com base no trabalho representa objetivamente duas possibilidades ou, se quisermos, dois modelos possíveis a partir de um princípio educativo no mundo do trabalho ou de sua ausência:

1. O mundo do trabalho como fomentador de um homem funcional, que existe e se forma no trabalho, com o claro objetivo de manutenção do status quo vigente. Aqui, o mundo do trabalho opera efeitos de subordinação e alienação.

2. O mundo do trabalho como fomentador de um homem integral (total), que existe e se forma no trabalho, com o claro objetivo de transformação do status quo vigente. Aqui, o mundo do trabalho opera efeitos de emancipação.

Emancipar é articular as forças individuais dentro de um contexto coletivo de produção. Necessariamente, essas forças individuais somadas 
(coletivas) se tornam o pressuposto de um processo educativo longo e penoso, o qual permitirá ao trabalhador acumular as condições objetivas de sua autoemancipação.

Por evidente, a condição fundamental para um diálogo construtivo entre academia e mundo do trabalho passa por um equilíbrio de poderes, do poder de dizer a verdade. Esse equilíbrio somente será factível a partir de um trabalho emancipador e de uma universidade que acredita na extensão como fonte de produção de conhecimentos.

\section{REFERÊNCIAS}

ADORNO, T. W.; HORKHEIMER, M. Dialética do Esclarecimento. Traduzido por Guido Antonio de Almeida. Rio de Janeiro: Zahar, 1985. $224 \mathrm{p}$.

DUSSEL, E. Ética da libertação: na idade da globalização e da exclusão. Petrópolis: Vozes, 2000.

MAKARENKO, A. Poema pedagógico. São Paulo: Editora 34, 2005.

RAMIL, V. À beça. Álbum À beça. [S.1.]: Gravadora Capacete Records, 1995. [52:49]

RIBEIRO, M. Universidade brasileira pós-moderna: democratização x competência. Manaus: Universidade do Amazonas, 1999.

ROUSSEAU, J. J. Discours sur les sciences et les arts. Oeuvres Complètes, Paris, v. 2, 1971.

SANTOS, B. de S. Pela mão de Alice: o social e o político na pós-modernidade. São Paulo: Cortez, 1995, p. 187-233. 